\title{
Study on the Asset Impairment Accounting
}

\author{
Shipan Sun \\ School of Accounting, Shandong Economic University, Ji'nan 250014, China \\ E-mail:ssp_sie@163.com
}

$\mathrm{Xia} \mathrm{Xu}$

School of Information Management, Shandong Economic University, Ji'nan 250014, China

E-mail: x2dx@sina.com

\begin{abstract}
To better perfect and perform the new asset impairment standards, this article studies the theoretical base, the range and characters, and the accounting manipulation space about the asset impairment, and relative advices to perfect the asset impairment accounting are proposed finally.

Keywords: Market economy, Asset impairment, Asset impairment accounting space, Accounting objective

To standardize enterprise accounting behaviors such as recognition, measurement, and reporting, and ensure the quality of accounting information, according to the "Accounting Law of the People's Republic of China", the Ministry of Finance issued the Accounting Standards for Business (including the basic standards and 38 concrete standards), and the law had been implemented in the listed companies and other part enterprises from Jan 1, 2007, and for enterprises or companies which implemented the new accounting standards, the influences were extensive. In this article, the theoretical base, the range and characters, and the accounting manipulation space about the asset impairment are researched as follows, and relative advices to perfect the asset impairment accounting are proposed finally.
\end{abstract}

\section{Theoretical base of the asset impairment}

The value of asset is radically decided by the market economy and the trades and events happening in the economy, because the real value of the asset should be realized or proved by the future trades or events. The theoretical base of the asset impairment exists in two aspects.

\subsection{The market economy theory}

As an economic system, the market economy could be compared with the planning economy of autarky and the mixed economy, and it is not the theoretical innovation of China, and it had existed early in the western economics. Comparing with other economic systems, the market economy has very distinct characters. (1) Freedom. The market economy specially advocates the free competition. According to this theory, all enterprises and users could compete for all market resources and products such as capital, technology, talent, land, and information, and the result of the competition is that all participation parties could maximize their own benefits. (2) Uncertainty. This uncertainty comes from the adjustment of "invisible hand" and the fluctuation of the market economy itself. The freedom will definitely induce the existence of the uncertainty, and the uncertainty will also embody the essential character of the market economy, i.e. the freedom. Therefore, future trades or events happening in the market economy will bring uncertain economic benefits for enterprises, and not only enterprises but also accounting personnel could not ensure that, so the uncertainty of this future economic benefit may induce that the future economic benefit will be lower than the book-value of the asset, and the asset impairment occurs. Of course, the impairment may not happen, and the maintenance of value even the increase of value may happen. Therefore, the essential characters of the market economy will decide that the value of asset may change (including the asset impairment).

\subsection{The accounting objective theory}

Though the value of asset could not be confirmed by the accounting personnel, but it should be honestly reported to investors, so even if the value of asset is not exact, the inaccurate asset value report should be reported to the user of information, which is not only the embodiment of the accounting objective, but the responsibility of the accounting. To reduce the uncertainty to the minimum degree, and effectively avoid potential disclosure responsibility and risk, enterprises and accounting personnel should test and confirm the asset impairment, and provide more reliable asset value information report to the users of information, and the confirmation of the asset 
impairment would enhance the decision serviceability of the accounting information, and maximally protect the disclosure subject of the accounting information. Therefore, the theory of accounting objective decides the confirmation of the asset impairment.

\section{The range and characters of the asset impairment}

Theoretical speaking, the impairment exists in all assets, including the currency capitals. At present, the new standards of China mainly standardize the items and range of the asset impairment, and these assets include the trading financial assets, the accounts receivables, the stock, the available-for-sale financial assets, the held-to-maturity investments, the long-term equity investments, the investment real estate, the fixed assets, the construction in process, the project materials, the productive biological assets, the oil and gas assets, the intangible assets, and the goodwill.

The asset impairments which should be confirmed in the new standards mainly have following characters.

\subsection{Numerous asset items should be confirmed as asset impairment}

The range of the asset impairment almost includes all asset projects. Because the standards are hard to grasp and operate, so some asset projects such as currency capitals and long-term prepaid expenses have not been required in the new standards to confirm the asset impairment.

\subsection{The causes inducing the asset impairment are very complex}

There are so many asset impairment items, and there are also so many complex causes to induce the asset impairment, including the interior causes of enterprise, and the exterior causes of enterprises. And these causes may come from not only the management of the market body, but also the whole environment of the market. For example, when the impairment of the consumed stock is confirmed, not only the market price of the product stock but also the predicted finished cost from stock production to the product stock should be considered. Enterprises are hard to control the market price, which is influenced by the product supply and demand relation and consumers' consumption favor in the whole economic market. But the predicted finished cost is influenced by the interior production technology and the management level of the enterprises.

Comparing with the enterprise accounting system, new accounting standards have a larger range of the asset impairment which should be required to confirm. Could this extending certainly make the information of asset and profit accounting of enterprise more real and reliable? Dialectically, on the one hand, the extending of the rage aims at the capitals watering and reporting of most assets for enterprise, and the new standards compulsorily regulate that the impairment of asset must be confirmed, and the asset and profit of enterprise must be checked, which is positive to obtain real information of asset for investors. On the other hand, the extending of range will increase the asset impairment accounting manipulation space, and the asset items which could be manipulated, and the concealment of impairment accounting manipulation will be more obvious. In addition, the influencing factors of asset impairment are very complex, so the asset impairment manipulation space is larger, which should be concerned in the implementation of new standards. The asset impairment accounting space will be mainly analyzed as follows, and when auditing personnel check the accounting reports of enterprise, these spaces should be concerned.

\section{Manipulation space analysis of the asset impairment accounting}

According to the characters of asset and the recognition and measurement requirements in the accounting standards, following representative asset impairment accounting manipulation spaces will be discussed.

\subsection{Trading financial assets}

The trading financial assets have two representative characters, (1) the initial and subsequent assets should be measured by the fair value, (2) the fair value change at the balance sheet date should be reckoned in the current profit. The author thinks that the impairment manipulation space of the trading financial assets mainly is that the classification division of the trading financial asset can be selected. Once a kind of financial asset is divided into the trading financial asset, it could not be divided into another kind of financial asset. This regulation could not only limit the type selection of the enterprise administration, but also make the enterprise to be more careful even "too" careful before its asset is divided into the trading financial asset. For example, to reduce the influence of the market price on the current profit of the enterprise and attract investors, the administration of the enterprise could directly appoint the assets belong to the trading financial asset as the available-for-sale financial asset, and the fair value of the available-for-sale financial asset will not influence the profit and loss. Once the asset is divided into the trading financial asset, it will be in the active trading markets such as share and bond, and its fair value could be easily obtained at any time, and in the ending measurement, the closing price of the trading 
financial asset could be the fair value, so without considering the condition of the investor's manipulation of the capital market, the measurement sum is fair, and it represents the value of the trading financial asset, and as viewed from this point, the manipulation space of the enterprise is limited.

\subsection{Stock}

The accounting spaces of the stock impairment include two aspects. The first one is that comparison method of the stock cost and the net realizable value can be selected. For example, generally, the impairment loss recognized by the single-time comparison method is the highest one, and the ending stock value is the lowest one, and the impairment loss recognized by the sum comparison method is the lowest one, and the value of the ending inventory is the highest one, and the classification comparison method is the middle one. Therefore, according the intention of the administration, it could select the comparison methods. In numerous stocks, some of them reduce their values, and some of them maintain their values, and some of them increase their values, so the impairment manipulation space is larger, and the enterprise has the right to select the stock comparison method, so the stock accounting space could be endowed for the enterprise, because different methods will induce different data of asset and profit, and when the capital market is not efficient fully, investors are difficult to distinguish whether the enterprise could manipulate the selection space. The second one is that the estimation of the net realizable value is changeable. The net realizable value equals to that the predicted sales price of the stock reduces the estimated finished cost, the estimated sales charge, and the estimated sum of relative taxes and charges. Therefore, except that he predicted sales price could be explained by the enterprise, other factors all need to be estimated, and the subjective space is large.

\subsection{Held-to-maturity investments}

The impairment accounting space of the held-to-maturity investments is mainly embodied in three aspects. First, the enterprise could manipulate the reclassification of the held-to-maturity investments. For example, the enterprise could reclassify the available-for-sale financial assets, which could round happened impairment loss from the profit sheet, because if the fair value of the available-for-sale doesn't fluctuate largely, it could be reckoned in the contributed surplus. Second, the scale standard of the held-to-maturity investments is not definite, and when the impairment is confirmed, the enterprise could randomly appoint two kinds of division standards to reduce the impairment loss. Third, the present value to predict the future cash flux is difficult to be confirmed, so the conformation of the impairment loss needs to be predicted. But to estimate the present value of the future cash flux needs three parameters, i.e. the future cash flux in each term, the period of the cash flow-in and the discount rate. These factors will be influenced randomly, for example, the cash flux can be estimated according to the financial budget and the growth rate of the administration layer of the enterprise, and the financial budget is established according to he will and prediction of the administration layer, so the present value of the future cash flux could be adjusted according to the will, so the impairment loss indirectly has large accounting manipulation space.

\subsection{Intangible assets}

The impairment manipulation space of the intangible assets is large too. First, the enterprise could manipulate the classification of the intangible assets. According to the regulation of the new standards, according to the certainty of useful life, the intangible assets can be divided into the intangible assets with limited useful life and the intangible assets with uncertain useful life. The author thought that it was difficult to confirm the impairment of the intangible assets with uncertain using life. The enterprise could manipulate the classification of the intangible assets to transfer or conceal the possible impairment loss. At the same time, the classification of intangible assets could create space to amortize the intangible assets for the enterprise. Second, the confirmation of the recoverable amount has large manipulation space. The recoverable amount could be confirmed according to the bigger difference that the fair value of the asset detracts the net amount of the disposal charge or the estimated present value of the future cash flux. The fair values of some intangible assets are difficult to be confirmed, and it is more difficult to estimate the present value. Therefore, the impairment of intangible assets is theoretically feasible, but the practice has larger manipulation space, and the auditing of relative information about intangible assets is more difficult. In fact, the comparison of the recoverable amount and the book value could be used to confirm whether the impairment items include the long-term equity investments, the investment real estate, the fixed assets, the productive biological assets, and the goodwill. Therefore, the enterprise could also manipulate the impairment space. 


\section{Advices to perfect the asset impairment accounting}

4.1 Further perfecting relative enterprise accounting standards and reducing the manipulation space of the asset impairment accounting

Because the accounting standards could provide the space of the accounting manipulation, so to reduce the asset impairment accounting manipulation space needs starting from the accounting standards and relative guidance, and the financial department should properly modify or perfect the standards according to the problems existing in the implementation or the standards with large manipulation space. Specially, to reduce the asset impairment accounting manipulation space is not to limit the accounting policy selection of the enterprise. For example, when test the impairment, some assets need to be reclassified according to their importance, and this classification could be flexible, and the final asset impairment results are multiple. Therefore, the importance should be defined scientifically and reasonably, for example, when the sum of the asset achieves certain proportion of the total asset, the enterprise should test whether the asset has the impairment alone. This regulation doesn't mean that the enterprise should classify the assets according to the importance, but mean that the classification reference should be more definite, so the man-made manipulation space of the asset impairment accounting could be reduced.

4.2 Quickening the training of the enterprise accounting officers and strengthening their vocational judgment ability

The professional judgment ability of accounting has been more used in the asset impairment accounting, and the implementation of new standards requires the accounting personnel more highly. Because the amount of enterprise is numerous, and the concrete situations are largely different, and the accounting personnel's abilities are different too, so it is not practical to train or instruct all enterprise accounting personnel's ability of asset impairment. Therefore, the financial department could specially train the financial mangers' asset impairment accounting in various enterprises, and help these enterprise to enhance the ability to use the new standards. This intentional training could not only enhance the enterprise accounting managers' ability of accounting operation, but also drive other common accounting personnel's level gradually.

4.3 Fully developing various active assets trading markets and making the market value information of assets to be acquired more easily

The confirmation of assets impairment needs not only sufficiently perfect standards, but also sufficiently active and developed exterior market of assets, and it is generally implemented by the book value and the market value of the asset, and the book value is a kind of recorded value which could be easily obtained by the book, but the market value is influenced by many factors, and it has many implementation modes. For example, according to the market value of the stock could be measured according to the achievable net realizable value of the holding stock. In addition, the fixed asset could be measured according to the receivable amount which could be drawn back by using the asset continually or disposing it once. It is obvious that the nicety of the asset impairment confirmation is decided by the exact market measurement of the asset value, which is very important for the confirmation.

At present, comparing with the non-financial asset, the market value of the financial asset is easier to be confirmed, but there still are many uncertain factors. Most non-financial assets lack in active trading market and the acquirement of the market value information is more difficult. It is a complex system engineer to cultivate the active trading market of assets, which comes down to many factors. In the short term, the author thinks that the asset transfer experience of the financial enterprises could be used for references, and cities could found the enterprise asset evaluation and trade center, and as a service agency, the center should persist in the market operation standards, and serve enterprises to confirm the asset value and transfer the assets. Relative departments could constitute relative laws or regulations, and relative asset trading market will emerge to adapt the development of the economy, and relative governmental departments should mainly cultivate relative markets of asset trading for enterprises and promote the formation of the enterprise asset trading market.

\section{References}

Finance Accounting Division Writing Group of Finance Ministry. (2007). Explanation of Enterprise Accounting Standards. Beijing: People Press. April, 2007.

Ge, Jiashu et al. (2002). Modern Western Accounting Theory. Xiamen: Xiamen University Press. Sep, 2007.

Securities Times. (2009). Shanghai Stock Exchange Will Strive to Establish the Professional Platform for the Financial Asset Trading. Securities Times. July, 14, 2009. A5. 